\title{
Autologous CISH-inactivated TILS
}

National Cancer Institute

\section{Source}

National Cancer Institute. Autologous CISH-inactivated TILs. NCI Thesaurus. Code C151926.

A preparation of autologous tumor-infiltrating lymphocytes (TILs) where the cytokineinducible $\mathrm{SH} 2$-containing protein gene $(\mathrm{CISH})$ has been inactivated using the clustered regularly interspaced short palindromic repeat (CRISPR)/CRISPR associated protein 9 (Cas9) editing system, containing guide RNA (gRNA) coupled to a recombinant form of the DNA endonuclease Cas9, with potential immunomodulating and antineoplastic activities. Using the CRISPR/Cas9 system, the autologous TILs are transfected, ex vivo, with a plasmid encoding for a gRNA that site-specifically targets and binds to the human $\mathrm{CISH}$ gene. Cas9 cleaves these specific DNA sites, which causes double strand breaks, disrupts the gene encoding $\mathrm{ClSH}$ and prevents transcription. Upon intravenous administration, the autologous CISH-inactivated TILS are able to induce a T-cellmediated immune response against tumor cells. $\mathrm{CISH}$, a member of the suppressor of cytokine signaling family (SOCS; cytokine-induced STAT inhibitor; ST AT-induced STAT inhibitor; SSI), is induced by T-cell receptor (TCR) stimulation. CISH plays a key role in the negative regulation of both $\mathrm{T}$-cell signaling and CT L-mediated tumor cell eradication. The knockout of the CISH gene enhances the expansion and anti-tumor activities of effector T-cells. 